\title{
“...POR UNA HELENA..." \\ FILOSOFÍA Y RETÓRICA EN EL MITO \\ DE LA MUJER MÁS BELLA
}

Mariano Nava Contreras

Universidad de los Andes. Venezuela

Resumen: se intenta una revisión del mito de Helena en cuatro momentos diferentes, tres de ellos pertenecientes a la literatura clásica griega y uno a la moderna: la épica homérica, el Encomio de Gorgias de Leontino, la tragedia euripídea y el poema homónimo de Yorgos Seferis. En los cuatro textos el mito sirve como modulador de cuatro mensajes diferentes, en los cuatro se adapta a formas discursivas diferentes y funciona en circunstancias y contextos históricos diferentes.

Palabras clave: Helena, Ilíada, Gorgias de Leontino, Eurípides, Seferis, mito, tradición clásica.

\section{“...FOR A HELEN". PHILOSOPHY, RHETORIC AND HISTORY IN THE MYTH OF THE MOST BEAUTIFUL WOMAN}

\begin{abstract}
A revision of the myth of Helen is tried in four different moments, three of them pertaining to the classical Greek literature and one of then to the Modern one: Homeric epic, the Encomium by Gorgias of Leontinus, the Euripide an tragedy and the homonymous poem by Giorgos Seferis. In the four texts the myth serves as a modulator of four different messages, in the four is adapted to different discursive forms and works in different historical circumstances and contexts.
\end{abstract}

Keywords: Helen, Iliad, Gorgias of Leontinus, Euripides, Seferis, Myth, Classical Tradition.

Recibido:16.08.2017 - Aceptado: 5.10.2017

\section{Correspondencia: Mariano Nava Contreras}

Email: marianonava@gmail.com

Licenciado en Letras Mención Lenguas y literaturas clásicas Universidad de los Andes. Doctor en Filología Clásica Universidad de Granada

Ap. Post. ${ }^{\circ}$ 20. IPOSTEL-Humboldt

Mérida 5101 VENEZUELA 
“Qué dices? ¿Por una simple nube sufrimos tanto?” Eurípides, Helena 707

"Ruiseñor ruiseñor ruiseñor, ¿Qué es dios? ¿Qué no es dios? ¿Y qué hay entre ambas cosas?” Yorgos Seferis, Helena

$\mathrm{E}$ n el tercer canto de la Ilíada se narra la escena en que aparece, por primera vez para la literatura, Helena. Cuenta Homero que se encontraba tejiendo en sus aposentos al interior del palacio de Príamo en Troya. La bella no sabe que en el campo de batalla teucros y aqueos han detenido la contienda y llegado a un acuerdo: Menelao y Alejandro se batirán en duelo por ella. Aquél que venza se la quedará y así terminará la guerra. Iris, la mensajera de los dioses, baja del Olimpo a avisarle y ella, apenas conteniendo el corazón en el pecho, corre a las murallas a presenciar el combate singular en que se juega su destino. Los ancianos de la ciudad la ven llegar vertiendo lágrimas y no pueden evitar los comentarios:

No hay que indignarse de que troyanos y aqueos de hermosas grebas

por semejante mujer tanto tiempo y tantos males hayan sufrido ¡Cuánto impresiona, de solo verla, el parecido con las diosas inmortales!

Pero aún así, siendo tan bella, váyase pronto a sus naves, no se convierta en una calamidad para nosotros, y después para nuestros hijos ${ }^{1}$.

1 Il. III 156-160. Para las citas de la Ilíada hemos tomado la traducción de Mariano Nava, Caracas, 2011. S. Pomeroy (1995) en su clásico estudio Goddesses, Whores, Wives \& Slaves (pág. 16), nos dice que este fragmento, tomado de la obra literaria más antigua que se conserva, nos provee de la evidencia de una experiencia femenina "tan fascinante como contradictoria". Acerca de la leyenda y el culto a Helena, cf. Pomeroy, S. (2007), Spartan Women, 114-118. 
Entonces el rey Príamo la invita a sentarse a su lado:

Ven aquí, hija mía, siéntate a mi lado

para que veas a tu primer marido, a tus parientes y amigos

-que no para mí eres tú la culpable de esto: son culpables los dioses, pues lanzaron contra mí la guerra de los aqueos que lágrimas siembra ${ }^{2}$.

La bella accede y se sienta junto al anciano. Entonces le responde:

Tanto pudor y respeto me inspiras, suegro querido.

¡En buena hora y de mala muerte me hubiera muerto

aquel día en que quise seguir a tu hijo, dejando tálamo y amigos, la hija mimada y las compañeras queridas!

Pero no fue así y me consumo llorando ${ }^{3}$.

A continuación reconoce junto al viejo a los caudillos griegos que se encuentran en la explanada. Agamenón Atrida, Odiseo, Ayante son divisados a lo lejos por la bella. Para cada uno hay un elogio, pero hay dos guerreros que busca especialmente y no alcanza a ver. Se trata de sus hermanos:

Cástor, que doma caballos, y Pólux, que es bueno en la pugna, hermanos de sangre que una misma madre parió conmigo.

O no han venido desde la amable Lacedemonia

o han venido en las naves que surcan el Ponto

y no quieren sumirse en la lucha de los varones

por temor de mezclarse con la vergüenza y gran deshonra que me rodea ${ }^{4}$.

2 Il. III 162-165.

3 Il. III 173-176.

4 Il. III 237-242. 
Vemos claramente en la primera configuración literaria del mito la presencia de los tres elementos que lo articulan: la belleza extraordinaria de Helena ${ }^{5}$, el adulterio que comete ${ }^{6}$ y la culpa ${ }^{7}$ y vergüenza que siente ${ }^{8}$. Así lo dirá en la Odisea años después, aquella noche en que recuerde junto a Telémaco y Menelao el día que los aqueos tomaron Troya:

...alegrábase mi pecho, pues ya el corazón me impulsaba a volver a mi hogar, y lloraba el error que Afrodita me inspirara al llevarme hasta allí de este suelo querido en el cual dejaba a mi hija, mi lecho y mi esposo... ${ }^{9}$

Según sus propias palabras, la falta que comete y que tanto la avergüenza no es del todo su culpa, sino que fue inspirada por Afrodita, quien la había ofrecido a Alejandro a cambio de ser elegida la más hermosa de las diosas, sobre Hera y Atenea, el día del célebre "juicio"10. Es un poco

5 Hécuba, la anciana reina de Troya, dirá en las Troyanas de Eurípides que "ella arrebata las miradas de los hombres, destruye las ciudades y pone fuego a las casas. Tal es su poder seductor" (Eur. Tr. 892-893. Traducción de José Luís Calvo Martínez, Madrid, 1995).

6 Safo (fr. 16 L.-P.) dice que Helena era "más hermosa que ningún ser humano", y que "abandonó a su honorable esposo y a Troya escapó, y nunca de su hija se acordó ni de sus padres, y es que, de su grado, la hizo errar el camino la diosa cipria" (traducción de Juan Ferraté, Barcelona, 2000).

7 Cf. M. Sousa Silva (2007). "Eurípides misógino”, en F. J. Campos Daroca et al., Las personas de Eurípides, 146: “Además de en la reprobación, la mujer adúltera incurre en el odio de sus víctimas. Es comprensible la reprobación vigorosa de Hécuba, troyana a quien la desvergüenza de Helena privó de la normalidad de su vida: casa, marido, hijos y el estatuto envidiable de soberana de Troya. Movida por un profundo resentimiento, la esposa de Príamo exige para la culpable un castigo ejemplar: simplemente la muerte (Tr. 1031-1032)".

8 Acerca de la culpa de Helena, cf. Konstan, D. (2010). Before Forgiveness. The Origins of a Moral Idea, 44 ss.

9 Od. Iv 269-264. Trad. José Manuel Pabon, Madrid, 1983.

10 Durante las bodas de Tetis y Peleo, se hallaban reunidas Hera, Atenea y Afrodita. Eris, la Discordia, lanzó en medio de ellas una manzana de oro, diciendo que sería para "la más bella". Inmediatamente surgió una disputa por saber a cuál de las tres diosas pertenecería la manzana. Entonces Zeus encargó a 
lo que también le había dicho el buen Príamo, recordemos, aquel día que atisbaban desde las murallas de Troya: que no era ella la culpable sino los dioses.

¿Hasta dónde llega, pues, nuestra responsabilidad sobre los errores que cometemos cuando somos inducidos por los mismos dioses? ¿Cómo podemos salvarnos si nuestro destino no está en nuestras manos? ¿Qué es entonces la justicia? No debe extrañarnos que el mito de Helena haya servido de inspiración para profundas reflexiones éticas. Tres siglos después de Homero, el sofista Gorgias de Leontino compondrá su Encomio de Helena. En él, pretende rebatir las cuatro acusaciones que se le hacen a la bella: 1) Si Helena marchó a Troya junto a Paris por designio de los dioses no puede ser culpada, pues no es posible oponerse a la voluntad de los dioses; 2) Si fue raptada a la fuerza, tampoco es su culpa, pues lo hizo contra su voluntad; 3) Si fue convencida para que lo hiciera, tampoco puede reprochársele el haber tomado una decisión persuadida de su conveniencia, 4) Y si lo hizo por amor, menos aún puede culpársele, pues los antiguos sabían muy bien que Eros es una fuerza divina e irresistible que controla el alma y la voluntad ${ }^{11}$.

En realidad, lo que le interesa a Gorgias es poner en evidencia el poder del $\log o s^{12}$, por el que la reputación de la adúltera más célebre quedaría limpia gracias al insospechado poder de la palabra. Dice Gorgias en su Encomio:

El logos es un señor muy poderoso que, con un cuerpo diminuto e imperceptible, lleva a cabo las más divinas hazañas. A través de los discursos, el alma se deja afectar por cierto sentimiento relacionado con venturas $\mathrm{y}$ desventuras de personas y cosas que nos son ajenos $[\ldots]$ Los discursos armoniosos,

Paris que eligiera a la más hermosa. Cada una prometió a éste un don si la elegía: Hera prometió el imperio de toda Asia; Atenea, la prudencia y la victoria en todos los combates, y Afrodita, el amor de Helena. Paris se decidió por Afrodita. Cf. Grimal, P. (1984). Diccionario de mitología griega y romana, 408-409.

11 Pernot, L. (2000). La Rhétorique dans l'Antiquité, 32.

12 Pratt. J. (2015). "On the Treshold of Rhetoric: Gorgias's Encomium of Helen", Classical Antiquity, 34, 1, 163-182. 
inspirados por los dioses, suscitan placer, disipando la tristeza. La fuerza de la palabra, que convive con la opinión del espíritu, lo fascina, lo convence y lo transforma por encantamiento ${ }^{13}$.

Esto significa, en última instancia, que la función del lenguaje no es transmitir la realidad de las cosas, sino que su ámbito es muy otro: el de la manipulación. No hay una identificación ontológica entre la palabra y la cosa. Sin embargo, a través de su capacidad de producir sentimientos y, por tanto, manipular las emociones ${ }^{14}$, el logos adquiere un lugar preponderante en tanto que instrumento de dominio político ${ }^{15}$. El Encomio de Helena en realidad es uno de los primeros tratados acerca de la argumentación, en el que la sofística da cuenta del poder de la palabra. Su contundente influencia se hará sentir en autores como Platón ${ }^{16}$ o Tucídides ${ }^{17}$.

Tampoco el drama ateniense escapó de la influencia del pensamiento sofístico $^{18}$. En el prólogo de la Helena de Eurípides, la bella cuenta la

13 Enc. Hel. 8-10. Cf. Caramés Sánchez, J. (2010). "Relación entre retórica y magia en el Elogio de Helena de Gorgias", en Ma. Ángeles Almela Lumbreras et al. (Coords.), Perfiles de Grecia y Roma. Actas del XII Congreso Español de Estudios Clásicos, vol. II, 371-378.

14 Buis, E. (2016). "La defensa de las emociones: Gorgias y la producción retórica de páthe en el Encomio de Helena", Thalia dixit, 11, 1-18.

15 Calvo, T. (1995). De los sofistas a Platón: política y pensamiento, 93-97.

16 El problema de la relación "natural" (katàphysin) o "arbitraria" (katànómon) entre la palabra y la cosa, así como sus consecuencias para la ciencia, será abordado por Platón especialmente en el Cratilo.

17 López Eire, A. (1988). "La oratoria”, en López Férez, J. A. (Ed.), Historia de la Literatura Griega, 740.

18 Como nota M. Lefkowitz, “el argumento de que los dioses no alientan conductas inmorales fue sostenido por los filósofos antes y durante la época de Eurípides. El dramaturgo intenta poner tales afirmaciones en boca de sus personajes en momentos de crisis en sus vidas, pues no pueden creer que los dioses hayan permitido los desastres en los que se ven envueltos". Cf. Lefkowitz, M. (2007). Women in GreekMyth,189. Para D. J. Conacher, "la naturaleza altamente retórica de la tragedia griega en general, y el carácter agonístico de muchas de las tragedias sofocleas y euripideas en particular, han sido hoy en día muy bien 
"verdad" de su triste historia ${ }^{19}$. En realidad, aquel día en que Alejandro eligió a Afrodita como la diosa más hermosa, Hera, en venganza, engañó al muchacho, haciendo que se acostara con un fantasma:

...no fui yo lo que abrazaba el hijo del rey Príamo, sino una imagen viva semejante a mí que la esposa de Zeus había fabricado con aire celeste. Y el creyó que me poseía, vana apariencia, sin poseerme [...] Hermes me había conducido envuelta en una nube a través de las profundidades del éter hasta la casa de Proteo, elegido por ser el más virtuoso de todos los mortales, a fin de que yo conservase para Menelao mi lecho inviolado. Y aquí estoy, mientras que mi desdichado esposo persigue a mis

reconocidas". Para un análisis retórico de algunos fragmentos de la Helena, cf. Conacher, D. J. (2003). "Rhetoric and Relevance in Euripidean Drama", en J. Mossman (edited by), Oxford Readings in Classical Studies. Euripides, 81-101. Asimismo cf. M. Sousa Silva, "Eurípides misógino", op. cit., pág. 160: "Con la progresiva influencia de la retórica sofística en el teatro de Eurípides, Helena puede unir a la belleza, ya de por sí convincente, la fuerza de los argumentos y defender, en un agón con Hécuba arbitrado por el propio soberano de Esparta, el derecho a la vida y al regreso a casa". Por su parte, J. de Romilly, en La modernitéd' Euripide $(1986,124)$, nos recordará que “ese gusto por las ideas y las discusiones, que entonces apasionaba a los atenienses, está presente por todo el teatro de Eurípides".

19 Una de las innovaciones más llamativas del drama euripideo es que los personajes principales y hasta los protagonistas, sean dioses o mortales, reciten el prólogo de las obras, lo que está reservado a esclavos o mensajeros en las tragedias de Esquilo o Sófocles. En el caso de la Helena de Eurípides, no es solo en el prólogo de este drama donde la heroína asume, como Sócrates de la Apología, su propia defensa. También en Las troyanas (vv. 914-965) afirma, entre otras cosas, haber sido "vendida por su belleza". Cf. Alaux, J. (2011). "Acting Myth. Athenian Drama", en Dowden, K. and Livingstone, N. (Edited by), A Companion to Greek Mythology, 136. Para la influencia del Encomio de Helena en Las troyanas de Eurípides, cf. Hall, E. (2010).Greek Tragedy. Suffering under the Sun, Oxford, 37. 
raptores al pie de las murallas de Ilión. Muchas almas han perecido por mi culpa a orillas del Escamandro, y maldicen por ello de mí, que tanto he sufrido, y me acusan de haber promovido esta terrible guerra traicionando a mi esposo ${ }^{20}$.

O sea que Helena nunca llegó a cometer el adulterio del que injustamente la acusaban ${ }^{21}$. O sea que la guerra que causó tantas muertes y la destrucción de Troya había ocurrido por un fantasma, por una ilusión, o como dijo el anciano mensajero de Menelao, "por una simple nube"22. A Egipto la había trasladado Hermes por orden de Hera, al reino de Proteo, y allí la encuentra Teucro años después, quien recala accidentalmente camino de Chipre, habiendo sido expulsado de su patria, Salamina, por su padre. Allí será donde la encuentre finalmente también Menelao, en un final feliz más propio de la Comedia Nueva, y aun de la novela helenística y bizantina que de la tradición trágica, como bien nota Carlos García Gual23.

Sabemos que la Helena de Eurípidesfue estrenada en el año 412 a.C. ${ }^{24}$, cuando Atenas entraba en el decimonoveno año de la guerra contra Esparta $^{25}$. Dos años antes la escuadra ateniense había sido destruida en el

20 Eur. Hel. 34-55. Trad.de Carlos García Gual, Madrid, 1998.

21 Ovidio, en su Heroida XVIIse hace eco de esta versión, según la cual Helena mantuvo siempre una conducta sin tacha: fama tamen clara est, et adhuc sine crimine vixi / et laudem de me nullus adulter habet (Her. XVII17-18).

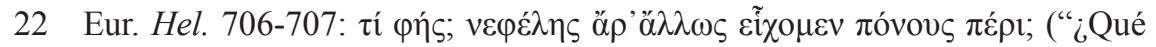
dices? ¿Por una simple nube sufrimos tanto?”).

23 García Gual, C. (1998). "Introducción a Helena", en Eurípides, Tragedias, vol. III, 11. Para el autor, se trata de "una tragedia sui generis que más parece una comedia fantástica o de enredo, pero con un elemento mítico muy desarrollado, lo que aproxima su contenido al de la novela helenística (Caritón, Jenofonte de Éfeso, Jámblico, Aquiles Tacio) y bizantina (Calímaco y Crisórroe)".

24 Según los escolios a las Tesmoforiantes de Aristófanes, vv. 1012 y 10601061.

25 Cf. Murray, G. (1978). Eurípides y su tiempo, 84: "Los historiadores helénicos, Tucídides a la cabeza, convienen en referir a la Guerra Peloponesia la progresiva degradación y amargura de la vida pública entre los griegos, y la reacción patente 
puerto de Siracusa, lo que daba al traste con la ilusión de invadir Sicilia. El éxito de esta campaña habría significado una clara ventaja para Atenas en la guerra. Sin embargo no había sido así, y ahora los atenienses se disponían a gastar sus últimos recursos en reconstruir su flota. Sabemos también que no fue Eurípides el autor de esta subversión del mito. Antes Estesícoro $^{26}$ y Heródoto ${ }^{27}$ ya la habían adelantado, si bien la truculencia y el dramatismo novelesco de esta versión pudieron haber seducido al dramaturgo de Salamina ${ }^{28}$. Quizás también por su pertinencia histórica, o tal vez porque, a través de la historia de Helena, una mujer espartana, el poeta haya querido hacernos reflexionar acerca del hecho de que aquello que mueve a la guerra, al igual que la belleza ${ }^{29}$, no es más que una ilusión ${ }^{30}$.

contra los sueños e ideales de antaño".

26 Palinodias. Page, D. (1968). Lyrica Graeca Selecta, Oxford, 1968, frs. 6263.Cf. también Plat. Phaedr. 243 a: "[Estesicoro] Privado de sus ojos, por su maledicencia contra Helena, no se quedó, como Homero, sin saber la causa de su ignorancia, sino que, a fuer de buen amigo de las Musas, la descubrió e inmediatamente, compuso,

No es cierto ese relato;

ni embarcaste en las naves de firme cubierta, ni llegaste a la fortaleza de Troya.

Y nada más que acabó de componer la llamada "palinodia", recobró la vista". Trad. de C. García Gual, Madrid, 2000.

27 Hdt. II 112-120.

28 Otras tragedias dedicadas al mito de Helena son la de Ión de Quíos ( $\operatorname{Tr} G F$ I 19 F 43a-49a) y las de Sófocles (La petición de Helena, frs. 176-180 a Radt; La violación de Helena, Tr GF IV págs. 180-181, y La boda de Helena, frs- 180184 Radt). Además se atribuyen a Teodectes y Diógenes sendas tragedias con su nombre ( $\operatorname{Tr} G F$ I 72 F 3, 88 F 1b). Cf. Redondo Moyano, E., "La Helena de Eurípides y los roles de género", en De Martino, F. y Morenilla, C. (Editores), La redefinición del rôle de la mujer por el escenario de la guerra, Bari, 2010, pág. 285, n. 1 .

29 Ov. Met. xv 232-236: "Llora también, al ver en el espejo las arrugas de la vejez, la hija de Tíndaro y se pregunta por qué fue raptada dos veces. ¡Oh tiempo que todo devoras, y tú, envidiosa vejez que, hincando el diente pútrido del tiempo, todo lo consumes poco a poco con la lenta muerte!".

30 Alaux, J., "Acting Myth. Athenian Drama”, op. cit., 149. 
En efecto, el gran problema que se plantea en la Helena de Eurípides es, nada menos, que el de distinguir la apariencia de la realidad ${ }^{31}$. Así lo dice el mismo coro cuando canta:

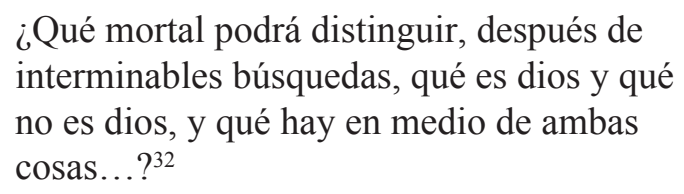

Como dice Jacqueline de Romilly, "Eurípides decide construir toda una tragedia a partir de una situación falsa desde el comienzo" ${ }^{33}$. En palabras de E. Hall en su Greek Tragedy ${ }^{34}$,

Helena confronta paradojas ontológicas, especialmente las problemáticas nociones de subjetividad, el yo y la identidad: ¿quién es la verdadera Helena? Si Helena de Troya no causó la guerra de Troya, entonces ¿quién es el objeto de la obra literaria? En términos semióticos, ¿cómo puede el significante, el nombre propio de Helena, estar tan abiertamente separado físicamente, éticamente, psicológicamente de la mujer que significa?

31 Idem. Como nota E. Hall (Greek Tragedy, op. cit., 270), "en tres de las obras fechadas durante la última década de la vida de Eurípides, Helena aparece como personaje (Las troyanas, Helena y Orestes). En su Helena del año 412 a.C., Eurípides se vale de la versión del mito que afirmaba que no había sido la propia heroína la que había ido a Troya, sino un simulacro en forma de nube. A través de esta versión, Eurípides fue capaz de utilizar a la mítica heroína para explorar cuestiones planteadas por filósofos contemporáneos en el campo de la ontología (¿qué es ser?) y de la epistemología (¿cómo conocemos las cosas?)”.

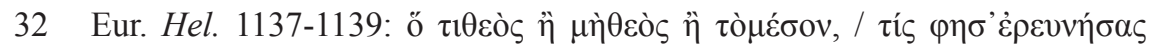

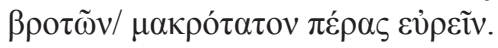

33 De Romilly, J., La modernité d'Euripide, op. cit., 147.

34 Op. cit., pág. 281. 
En este sentido, no dejamos de recordar aquellos versos en que Píndaro llama al hombre "sueño de un sombra" 35 . Platón, al hablar del verdadero placer y del amor en la República, tampoco dejará de recordar esta variante del mito de Helena, quien hizo nacer "en los insensatos unos mutuos y furiosos amores, por los cuales luchan como cuenta Estesícoro que, por ignorancia de la verdad, se luchó ante Troya en torno a la apariencia de Helena" 36 .

Se trata de la variante del mito que también recogerá Yorgos Seferis en su poema Helena. Aquí Teucro, que como hemos dicho, ha visto a Helena en Egipto, finalmente llega a Chipre y lo cuenta. La filiación intertextual con el drama euripideo es clara:

Poeta ruiseñor,

en una noche como esta en la costa de Proteo

te escucharon las esclavas espartanas y empezaron el

lamento,

y entre ellas -quién lo diría- ¡Helena!

La que perseguíamos durante años en el Escamandro.

Estaba allá, en los bordes del desierto: la toqué, me habló:

"No es verdad, no es verdad" exclamaba.

"No subí al navío de azulada proa.

Nunca pisé la intrépida Troya”.

Con su estrecho corpiño, el sol en los cabellos, y ese su porte

sombras y sonrisas por doquier

en los hombros en los muslos en las rodillas;

piel con vida, y los ojos

de grandes párpados,

35 Pind. Pit.VIII 95-96: “¡Seres de un día! ¿Qué es uno? ¿Qué no es? ¡Sueño de una sombra es el hombre!” (Trad. de Alfonso Ortega, Madrid, 1995).

36 Plat. Rep. 586 c. Trad. de José Manuel Pabón y Manuel Fernández-Galiano, Madrid, 1997. Para otras versiones y pervivencia del mito en la literatura helenística y romana, cf. Saquero Suárez-Sotomonte, P. (2014). "Helena, una

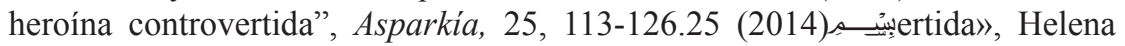
muerte»enido al de la novela helenta obra me 
estaba allí, en la ribera de un Delta

Nada en Troya - un fantasma.

¿Y en Troya?

Así lo quisieron los dioses.

Y Paris con una sombra dormía cual si fuese un

verdadero ser;

y diez años nos matamos nosotros por Helena.

Un gran dolor sobre la Hélade ha caído.

Cuántos cuerpos arrojados

a las fauces del mar, a las fauces de la tierra;

tantas almas

entregadas a las muelas del molino, como el trigo.

Y los ríos hacían crecer la sangre en el barro

por un ondular de lino por una nube

por el estremecimiento de una mariposa la pluma de un cisne

por una camisa vacía, por una Helena.

¿Y mi hermano?

Ruiseñor ruiseñor ruiseñor,

¿Qué es Dios? ¿Qué no es Dios? ¿Y qué hay entre ambas cosas? ${ }^{37}$

Helena forma parte del poemario Bitácora III, que fue publicado en el año 1955 bajo el nombre original de Chipre, donde el oráculo me predijo ${ }^{38}$. Sin embargo, el mismo poeta cuenta que casi todos los poemas

37 Trad. Miguel Castillo Didier, Santiago de Chile, 2014.

38 Como nota Linos Politis en su Historia de la literatura griega moderna (1973, 235), la frase es precisamente de la Helena de Eurípides (vv. 148-149). En la tragedia, Teucro arriba a Egipto huyendo de Salamina, de donde su padre Telamón lo ha expulsado por no haber impedido el suicidio de su hermano Ayax. Teucro inicia así un largo viaje hacia Chipre, donde el oráculo le ha vaticinado que fundará una ciudad llamada Nueva Salamina, en recuerdo de su patria. Se trata del mito subyacente al poema de Seferis, en que Teucro habla en primera persona. En cuanto al poemario, es en la segunda edición de 1959 cuando es

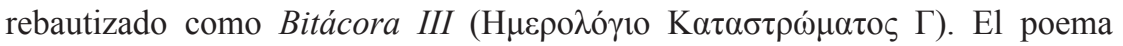


que lo componen "se le dieron" en otoño de 1953, cuando estuvo por primera vez en Chipre ${ }^{39}$. Hacía cerca de un año que había sido nombrado embajador de Grecia para el Líbano, Siria, Jordania e Irak, con sede en Beirut. En ese momento, Chipre es objeto de una grave disputa entre Grecia y Gran Bretaña, bajo cuya administración se encuentra la isla desde $1878^{40}$. Los chipriotas desean independizarse de los británicos y unirse políticamente a Grecia, lo que se conoce como la énosis, proyecto que fue vigorosamente apoyado por los griegos ${ }^{41}$. Gran Bretaña, por su parte, considera que la isla es estratégica para sus intereses, pues controla la ruta del petróleo entre el Medio Oriente y Europa ${ }^{42}$. Es la difícil circunstancia que debe afrontar Seferis como diplomático griego. Como embajador viajará en dos oportunidades a Chipre, en noviembre de 1953 y en agosto de 1954. Entonces querrá conocer profundamente la isla y su cultura, unida desde siempre y por tantas razones a la cultura griega ${ }^{43}$.

Helena ha sido traducido al español por José Alsina (1968), Pedro Bádenas de la Peña (1986), José Antonio Moreno Jurado (1988 y 1997), Ramón Irigoyen (1989), Pedro Ignacio Vicuña (1989), Gregoria Núñez Esteban (1994), Selma Ancira y Francisco Segovia (2012) y Miguel Castillo Didier (2014). Para un análisis histórico y literario del poema, con invaluables datos biográficos del autor, cf. Pociña Pérez, A. (2013). "Creación y tradición clásica en el poema Helena de Seferis", Flor. Il.,24, 199-217.

39 Castillo Didier, M. (2014). "Estudio introductorio", Seferis integro, 123-124.

40 De hecho, Chipre fue formalmente anexada a Gran Bretaña en 1914 y se convirtió en colonia de la corona británica en 1925. Cf. Clogg, R. (2013). A Concise History of Greece, 147.

41 Cf. Woodhouse, C. M. (1998).Modern Greece. A Short History, 269: "El deseo de los griegos de que Chipre se uniera con Grecia (énosis) era fuerte, virtualmente unánime y tenía profundas raíces, especialmente entre las cuatro quintas partes de población chipriota que era griega en el lenguaje, los sentimientos y la religión. Ningún tipo de argumento racional tenía valor contra él".

42 Vacalópoulos, A. (1995). Historia de Grecia Moderna 1204-1985, 343.

43 Seferis se compenetrará de tal manera con la cultura y con la causa chipriota que en 1956 formará parte de la delegación griega que toma parte en las negociaciones sobre la isla en las Naciones Unidas. Posteriormente, en 1958, formará parte de las conversaciones de París, ya como embajador en Londres, e igualmente un año después en Zurich. Cf. Castillo Didier, M., "Estudio introductorio", op. cit., 146. 
Pájaro plañidero,

en Chipre, besada por el mar

que el destino quiso me recordara a la patria, anclé solo en esta leyenda, si es verdad que esto es una leyenda, si es que los hombres no volverán a caer en el viejo engaño de los dioses; si es verdad que algún otro Teucro, después de los años, o algún Ayante o Príamo o Hécuba o algún desconocido, anónimo, que sin embargo vio un Escamandro desbordado de cadáveres, tiene en su destino el escuchar mensajeros que vengan a decir que tanto dolor tanta vida se fueron al abismo por una túnica vacía por una Helena.

Yorgos Seferiadis nació en Esmirna en 1900, cuando la ciudad era un emporio comercial y cultural griego enclavado en la costa oriental del Egeo. En 1919 estalla la guerra greco-turca y el poeta debe refugiarse en Atenas junto con su familia. En 1922 su ciudad natal es destruida hasta los cimientos, lo que la historia moderna de Grecia recuerda como "la catástrofe del Asia Menor" ${ }^{44}$, y Seferis no volverá a ver a su patria hasta

44 Los terribles sucesos bélicos que debe vivir el joven Yorgos marcarán sin duda el carácter de su poesía. Para Dimitris Angelís, "no es de extrañar que la generación literaria más importante sea la Generación del 30, un grupo de literatos de origen burgués (Seferis, Elytis, Venezis, Myrivilis, Terzakis, Embirikós y otros), que tras la catástrofe de Asia Menor buscaba redefinir el significado de la identidad griega -como de igual forma lo hizo, prácticamente en el mismo período, la Generación española del 27" (cf. D. Angelís, D. [2015]. "El libro griego en los años de crisis", El rapto de Europa, 28, 41-48). M. Castillo Didier ("La poesía de Yogos Seferis", en García Álvarez, C. y Castillo Didier, M. [2000]. Yorgos Seferis [1900-1971]. El poeta ensayista, 15-16) dice 
que tenga cincuenta años ${ }^{45}$. En 1918 marcha a París a estudiar Derecho. De vuelta en Atenas, comienza a trabajar en el Ministerio de Relaciones Exteriores. En abril de 1941, ante la invasión alemana, el poeta debe abandonar Atenas junto al resto del gobierno, primero a Creta y después a Alejandría ${ }^{46}$, junto a "las playas de Proteo" de su poema. Entre 1941 y 1944 sigue al gobierno griego en el exilio por Egipto, Sudáfrica, Inglaterra

que "El drama del Asia Menor influyó fuertemente en todos los aspectos de la vida de Grecia y marcó el espíritu de más de una generación. Su reflejo en la literatura es muy vasto y variado. Pero es en los escritores procedentes de aquellas tierras que fueron griegas donde la tragedia pudo dejar su huella más auténtica. Y entre ellos, es en Seferis donde encontramos su transmutación más honda en poesía, su universalización más notable". Y en otro lugar: "la poesía seferiana es inseparable del sino trágico de aquellos griegos que - tras la visión casi concreta de una "liberación" ansiada por siglos (establecimiento de la autoridad griega en Esmirna en 1919, proclamación de la Provincia de Jonia y aproximación del ejército helénico a Constantinopla) — sintieron y padecieron en 1922 el desencadenamiento de una tempestad de sangre, cuyo desenlace fue su trasplante a la metrópoli europea y la desaparición de las comunidades del Asia Menor, Capadocia y el Ponto" (cf. M. Castillo Didier, M. [2004]. Un milenio de poesía griega,Santiago de Chile, s/pág.). Por su parte, Kimon Friar dirá que la poesía de Seferis "trata los temas de la ruina y la desolación, el gozo y la melancolía de su país, el recurrente tema de la expatriación y el destino de las pequeñas naciones acerca de las que él sabe de primera mano por su propia experiencia como diplomático en su tierra y en otras tierras" (cf. K. Friar, K. [1951]. "Contemporary Greek Poetry", Poetry, 78, 3, 145-151).

45 "Y viajará siempre. Viajará al dejar la tierra patria para siempre, viajará para estudiar, viajará en su trabajo como diplomático, viajará durante los años oscuros de la ocupación y podrá meditar en la ciudad de Kavafis. Será un náufrago en un islote desierto o en un cruel peñasco, al que le hace arder el alma la idea del retorno" (cf. Castillo Didier, M., "La poesía de Yorgos Seferis", op. cit., 29). Cf. igualmente López Jimeno, A. (2002). "Seferis o el desarraigo", Giorgos Seferis. 100 años de su nacimiento. Actas del III Encuentro sobre Grecia, Granada, 161174.

46 Seferis llegará a esta ciudad ocho años después de la muerte de Kavafis, el gran poeta griego de Alejandría. Sin embargo, las conexiones e influencias de la poesía de Kavafis sobre la de Seferis han sido profusamente estudiadas. Cf. H. Gifford, H. (1987). "Seferis and Cavafy", Grand Street, 6, 4, 245-256. Para las actividades políticas y literarias de Seferis durante estos años, cf. H. Gifford, H. (1986). "George Seferis during the War", Grand Street, 5, 2, 175-186. 
e Italia. De regreso a Atenas en noviembre de 1944 estalla la guerra civil. Dos meses más tarde parte como diplomático a Londres hasta febrero de 1948, cuando lo tenemos en Ankara como Consejero en la embajada turca. En 1951 vuelve a Londres y un año más tarde es nombrado embajador en Beirut. Un año más tarde será su primera visita a Chipre ${ }^{47}$.

Seferis escribió su Helena en 1953, diez años antes de que le concedieran el Premio Nobel de Literatura y después de siete años sin escribir poesía. Como un decepcionado Teucro que llega a su nueva patria, la isla "besada por el mar", $\theta \alpha \lambda \alpha \sigma \sigma o \varphi$ í $\eta \tau \eta$, habiendo descubierto la gran mentira de Helena, Seferis quiere advertir a los suyos que no caigan en la trampa de los dioses, que no vuelvan a ser víctimas de su capricho para que nunca más vuelva a llenarse el Escamandro de cadáveres. Que nunca más tanto dolor y tanta muerte sean por una nube, por una túnica vacía. El mito de la mujer más bella, que antes había inspirado a rapsodas, oradores y filósofos, volvía como excusa para un poeta pacifista.

\section{REFERENCIAS BIBLIOGRÁFICAS:}

ALAUX, J. (2011). "Acting Myth. Athenian Drama", en Dowden, K. and Livingstone, N. (Edited by), A companion to Greek Mythology, West Sussex, U.K.:Blackwell Publishers, 141-156.

ANGELÍS, D. (2015). "El libro griego en los años de crisis", El rapto de Europa, 28, 41-48.

BUIS, E. (2016). "La defensa de las emociones: Gorgias y la producción retórica de páthe en el Encomio de Helena", Thalia dixit, 11, 1-18.

CALVO, T. (1995). De los sofistas a Platón: política y pensamiento, Madrid: Ediciones Pedagógicas.

CARAMÉS SÁNCHEZ, J. (2010). "Relación entre retórica y magia en el Elogio de Helena de Gorgias", en Ma. Ángeles Almela Lumbreras et al. (Coords.), Perfiles de Grecia y Roma. Actas del XII Congreso Español de Estudios Clásicos, Madrid: Sociedad Española de Estudios Clásicos, vol. II, 371378 .

CASTILlO DIDIER, M. (2000). "La poesía de Yorgos Seferis", en García Álvarez, C. y Castillo Didier, M. Yorgos Seferis [1900-1971]. El poeta-el ensayista, Santiago de Chile: Centro de Estudios Griegos, Universidad de Chile, 7-37.

47 Para una cronología de la vida del poeta, cf. Castillo Didier, M., "Estudio introductorio", op. cit., 139-149. 
, (1972). "Seferis, el poeta del país desaparecido", Byzantion Nea Hellás, 2, 71-134.

, (1966). "Seferis, el último poeta de la Jonia helénica", Boletín de la Universidad de Chile, 71-72.

,. (1979). "Seferis: lo antiguo y lo contemporáneo", Vetera et nova, 9.

, (2004). Un milenio de poesía griega. Del siglo X al XX, Santiago de Chile: Universidad de Chile.

CLOGG, R. (2013). A Concise History of Greece, Cambridge: Cambridge University Press.

CONACHER, D. J. (2003). "Rhetoric and Relevance in Euripidean Drama", en J.

Mossman (edited by), Oxford Readings in Classical Studies. Euripides,

Oxford, Oxford University Press, 81-101.

FRIAR, K. (1951). “Contemporary Greek Poetry”, Poetry, 78, 3, 145-151.

GIFFORD, H. (2986). "George Seferis during the War", Grand Street, 5, 2, 175186.

GIFFORD, K. (1987). "Seferis and Cavafy", Grand Street, 6,4, 245-256.

GRIMAL, P. (1984).Diccionario de mitología griega y romana, Barcelona: Paidós.

HALL, E. (2010). Greek Tragedy. Suffering under the Sun, Oxford: Oxford University Press.

KONSTAN, D. (2010). Before Forgiveness. The Origins of a Moral Idea, Cambridge: Cambridge University Press.

LEFKOWITZ, M. (2007).Women in Greek Myth, Baltimore: The John Hopkins University Press.

LÓPEZ EIRE, A. (1988). "La oratoria”, en López Férez, J. A. (Ed.), Historia de la Literatura Griega, Madrid: Ediciones Cátedra.

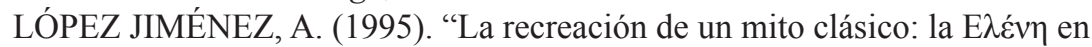
"Yorgos Seferis y el absurdo de la guerra", en Nieto Ibáñez, J., Estudios de religión y mito en Grecia y Roma, León: Universidad de León, 283295.

SEFERIS, Y. (2002). "Seferis o el desarraigo", Giorgos Seferis. 100 años de su nacimiento. Actas del III Encuentro sobre Grecia, Granada: Centro de Estudios Bizantinos, Neogriegos y Chipriotas, 161-174.

MURRAY, G. (1978). Eurípides y su tiempo, México: Fondo de Cultura Económica.

PERNOT, L. (2000).La Rhétorique dans l'Antiquité, Paris: Librairie Générale Française.

POCIÑA PÉREZ, A. (2013). “Creación y tradición clásica en el poema Helena de Seferis", Flor. Il., 24, 199-217.

POLITIS, L. (1973). A History of Modern Greek Literature, Oxford: Clarendon Press. 
POMEROY, S. (1995). Goddesses, Whores, Wives, \& Slaves. Women in Classical Antiquity, London: Pimlico.

POMEROY, S. (2007). Spartan Women, Oxford: Oxford University Press.

PRATT. J. (2015). "On the Treshold of Rhetoric: Gorgias's Encomium of Helen", ClassicalAntiquity,34, 1, 163-182.

REDONDO MOYANO, E. (2010). "La Helena de Eurípides y los roles de género", en De Martino, F. y Morenilla, C. (Editores), La redefinición del rôle de la mujer por el escenario de la guerra, Bari: Levante Editori, 285-308.

DE ROMILLY, J., La modernité d'Euripide, Presses Universitaires de France, Paris, 1986.

SAQUERO SUÁREZ-SOTOMONTE, P. (2014). "Helena, una heroína controvertida", Asparkía, 25, 113-126.

SEFERIS, Y. (2014). Seferis íntegro, traducción y estudio de Miguel Castillo Didier, Santiago de Chile: Editorial Tres puntos.

SOUSA SILVA, M. (2007). "Eurípides misógino", en F. J. Campos Daroca et al., Las personas de Eurípides, Amsterdam: Adolf M. Hakkert - Publisher, 133-190.

VACALÓPOULOS, A. (1995). Historia de Grecia Moderna 1204-1985, traducción de Nikiforos Nikolaides, Santiago de Chile: Universidad de Chile.

WOODHOUSE, C. M. (1998). Modern Greece. A Short History, London: Faber and Faber. 